\title{
BMJ Open Editors' and authors' individual conflicts of interest disclosure and journal transparency. A cross-sectional study of high-impact medical specialty journals
}

\author{
Rafael Dal-Ré, ${ }^{\oplus 1}$ Arthur L Caplan, ${ }^{2}$ Ana Marusic ${ }^{\circ} 3$
}

To cite: Dal-Ré R, Caplan AL, Marusic A. Editors' and authors' individual conflicts of interest disclosure and journal transparency. A cross-sectiona study of high-impact medical specialty journals. BMJ Open 2019;9:e029796. doi:10.1136/ bmjopen-2019-029796

- Prepublication history for this paper is available online. To view these files please visit the journal online (http://dx.doi org/10.1136/bmjopen-2019029796).

Received 12 February 2019 Revised 04 July 2019 Accepted 09 July 2019

Check for updates

(C) Author(s) (or their employer(s)) 2019. Re-use permitted under CC BY-NC. No commercial re-use. See rights and permissions. Published by BMJ.

${ }^{1}$ Epidemiology Unit, Health Research Institute-Fundación Jiménez Díaz University Hospital, Universidad Autónoma de Madrid, Madrid, Spain

${ }^{2}$ Division of Medical Ethics,

School of Medicine, NYU Langone Medical Center, New York City, New York, USA

${ }^{3}$ Department of Research in Biomedicine and Health, University of Split School of Medicine, Split, Croatia

Correspondence to Dr Rafael Dal-Ré; rafael.dalre@quironsalud.es

\section{ABSTRACT}

Objective To assess the fulfilment of authors' and editors' individual disclosure of potential conflicts of interest in a group of highly influential medicine journals across a variety of specialties.

Design Cross-sectional analysis.

Setting and participants Top-ranked five journals as per 2017 Journal Citation Report impact factor of 26 medical, surgery and imaging specialties.

Interventions Observational analysis.

Primary and secondary outcome measures Percentage of journals requiring disclosure of authors' and editors' individual potential conflicts of interest (Col). Journals that were listed as followers of the International Committee of Medical Journal Editors (ICMJE) Recommendations, members of the Committee on Publication Ethics (COPE) and linked to a third party (ie, college, professional association/society, public institution).

Results Although 99\% (129/130) of journals required author's Col disclosure, only $12 \%$ (16/130) reported individual editors' potential Cols. Forty-five per cent (58/130) of journals were followers of the ICMJE Recommendations, and 73\% (95/130) were COPE members. Most (69\%; 90/130) were linked to a college, professional society/association or public institution. Only one journal did not have policies on individual authors' and editors' Col disclosure.

Conclusion Very few high-impact medical journals disclosed their editorial teams' individual potential Cols-conversely, almost all required disclosure of authors' individual Cols. Journal followers of the ICMJE Recommendations should regularly disclose the editors' individual Cols, as this is the only legitimate way to ask the same transparency of authors.

\section{INTRODUCTION}

Recent highly publicised cases ${ }^{12}$ illustrated what has been suspected for many years, that many researchers do not appropriately disclose their financial conflicts of interest $(\mathrm{CoI})$, let alone disclose non-financial CoIs, about which there are differing opinions ${ }^{3}$ and lack of clear policies in most medical journals. ${ }^{4}$
Strengths and limitations of this study

- This is the first study comparing authors' and editors' individual disclosure of potential conflicts of interest in 130 leading journals from 26 medical specialties.

- A limitation is that we did not assess a representative sample of the whole population of medical journals. Also, we included only the information available in the public domain (journals' websites).

- The results obtained in this study may be an overestimation of how many journals require and comply with disclosure of authors' and editors' individual potential conflicts of interest.

The implementation of the Sunshine Act in the USA in 2013 reveals all industry payments received by all physicians practising in the USA through the Centers for Medicare \& Medicaid Services Open Payments Database (OPD; https://www.cms.gov/openpayments/). A study showed that $32 \%$ of oncologists working in the USA and authors of clinical trial articles published in six highly influential journals (two general/internal medicine journals and four oncology or haematology journals) failed to completely disclose industry payments from the company that sponsored the trials. ${ }^{5}$

Although authors' failure to disclose potential CoI is of grave concern, matters are worse when it comes to disclosure by editors and editorial teams. The Committee on Publication Ethics (COPE) - a highly respected professional committee providing leadership to editors, publishers and individuals on ethical publishing practices-recommends that 'editorial CoI should be declared, ideally publicly. ${ }^{6}$ The hugely influential International Committee of Medical Journal Editors (ICMJE) Recommendations for the Conduct, 
Reporting, Editing, and Publication of Scholarly Work in Medical Journals-which are followed by thousands of scholarly journals—state that editors should publish 'regular disclosure statements' about their own potential CoIs and those of their staff, and that guest editors should follow the same standards. ${ }^{7}$ This policy, however, is almost never followed. A review of the information in English posted on the websites of the 14 journal members of the ICMJE showed that only two of them (PLOS Medicine, The $B M /$ ) published individual declarations on editors' potential CoIs. ${ }^{8}$ A third ICMJE member journal (Annals of Internal Medicine) published its editorial team members' potential CoIs in online published original research articles, special articles and reviews as 'editors' disclosure' within the 'author, article and disclosure information.'

Practising physicians working as journal editors may receive industry payments and, hence, these financial CoIs should be disclosed to readers. Prior studies showed close to $50 \%$ of USA clinicians belonging to editorial teams in top-ranked medicine journals have received payments from industry. ${ }^{9-11}$

The aim of this study was to assess the fulfilment of authors' and editors' individual disclosure of potential CoI in a group of highly influential medicine journals across a variety of specialties.

\section{METHODS}

In November 2018 we searched the websites of highly influential journals for the policies on authors' and individual editors' potential CoI. These were the five top-ranked journals according to their 2017 Journal Citation Report (JCR) impact factor, in each of 26 different JCR categories within medicine, surgery and imaging. The search was conducted by alphabetical order of the JCR categories. If a journal was included in one category and was found to be in the top five of a subsequent category, the next journal of the top list of the latter category was included to avoid duplication. This resulted in the inclusion of 130 different journals.

The following data were retrieved: journal name; 2017 impact factor; journal link to a third party, that is, college, professional association or society or linked to a public institution, since this indicated the responsibility of a non-commercial organisation for a journal; if the journal was included at the ICMJE website as a follower of the ICMJE Recommendations; and if the journal was included on the COPE website as a member. A quality check process is required for COPE membership, but not for ICMJE Recommendations listing. In addition, at each journal website we searched if there was information for author's individual CoI disclosure at the time of manuscript submission and whether the journal provided individual editorial CoI declarations. This included all usual editorial positions, such as editors in chief, executive editors, deputy editors and associate editors or their equivalent. We presumed that these job positions would be involved in the editorial decision-making process. Data were retrieved by one of the authors, RDR; all the information from a random sample of $25 \%$ of the 130 journals was assessed by another author, AM, to check the consistency of the retrieved data.

\section{PATIENT AND PUBLIC INVOLVEMENT}

Neither patients nor any member of the public was involved in this study.

\section{RESULTS}

As shown in table 1, 99\% (129/130) of journals required authors' CoI disclosure, but only 12\% (16/130) reported individual editors' potential CoIs. There were 10 categories (out of the 26) with one journal reporting individual editors' potential CoIs, and three other categories (Gastroenterology and Hepatology, Oncology, and Respiratory Medicine) with two journals providing this information. Half of the categories (13/26) had no journal providing public disclosure of individual editors' CoIs. Only one journal (World Psychiatry) did not have policies on both authors' and editors' individual CoI disclosure. Out of 130 journals in the sample, $58(45 \%)$ were listed on the ICMJE Recommendations subscription list, and 95 (73\%) were COPE members. Thirty-eight (29\%) were both ICMJE Recommendations subscribers and COPE members-four of them belonging to Anaesthesia. Six categories had no journals subscribed to both ICMJE Recommendations and COPE. Fifteen journals (11.5\%)belonging to 11 categories-were neither followers of the ICMJE Recommendations nor COPE members. None of the five journals in the Immunology or Oncology categories were followers of the ICMJE Recommendations. None of the five Ophthalmology journals were COPE members.

A majority of journals in the sample $(69 \% ; 90 / 130)$ were linked to a college, professional society/association or public institution. Seven of the 26 categories had all five journals tied to a third party, whereas only one (Immunology) had five journals with no link to a third party. The two journals that were linked to a public institution were Emerging Infectious Diseases (from the USA Centers for Disease Control and Prevention, CDC) and Eurosurveillance (that belongs to the European Centre for Disease Prevention and Control, ECDC).

With regard to individual editors' CoI declarations, journal members of COPE and/or of the ICMJE Recommendations subscribers were not better in disclosures than other journals. Among those 16 journals that declared individual editors' CoIs, 10 were both followers of the ICMJE Recommendations and COPE members; the Journal of Clinical Oncology was neither a follower of the ICMJE Recommendations nor was a member of COPE.

None of the 22 journals listed in table 1 belonging to the Lancet, JAMA or Nature Reviews journal groups reported individual editors' potential CoI. Two journals belonging to the same group (Journal of the American College 


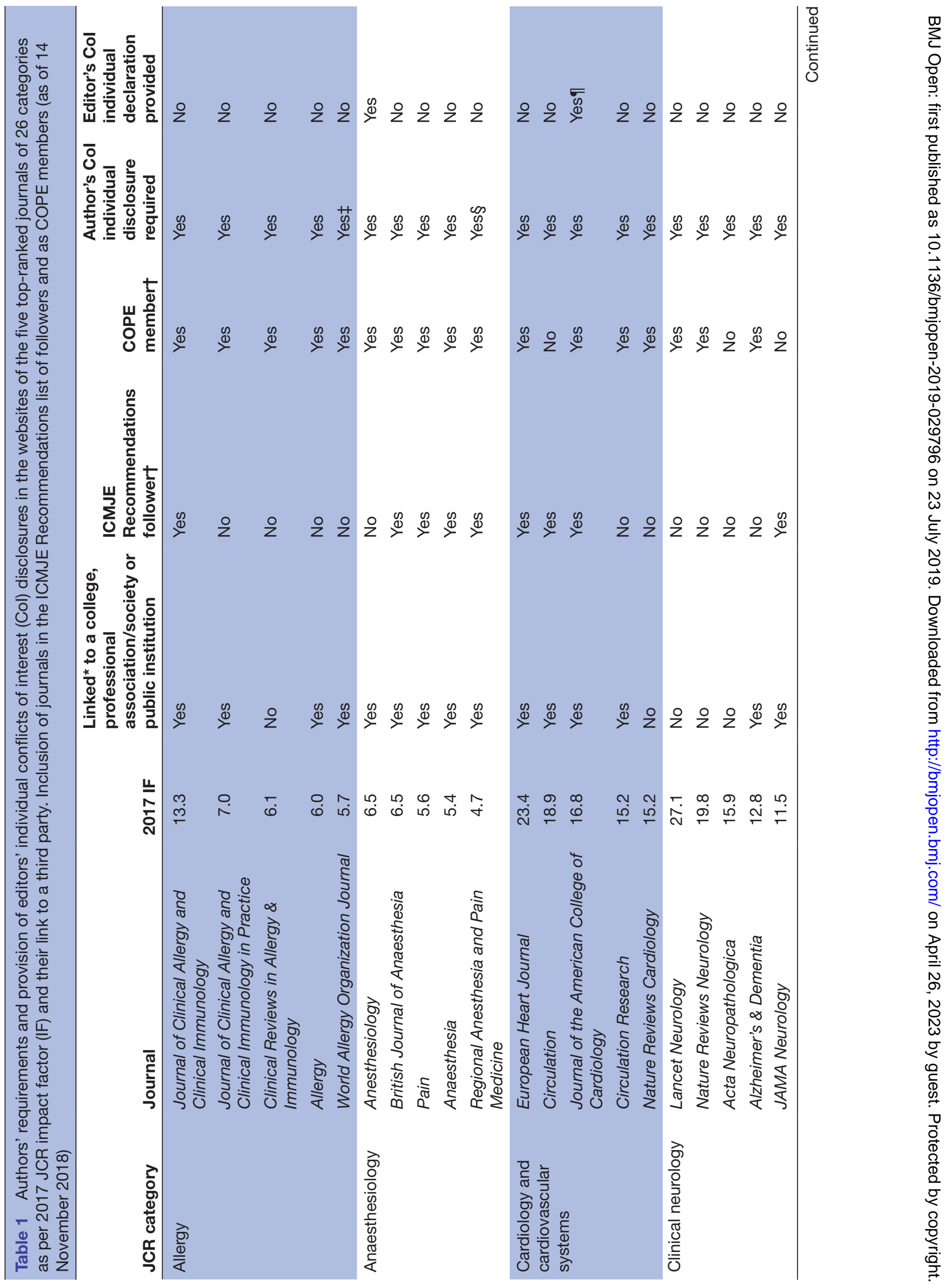




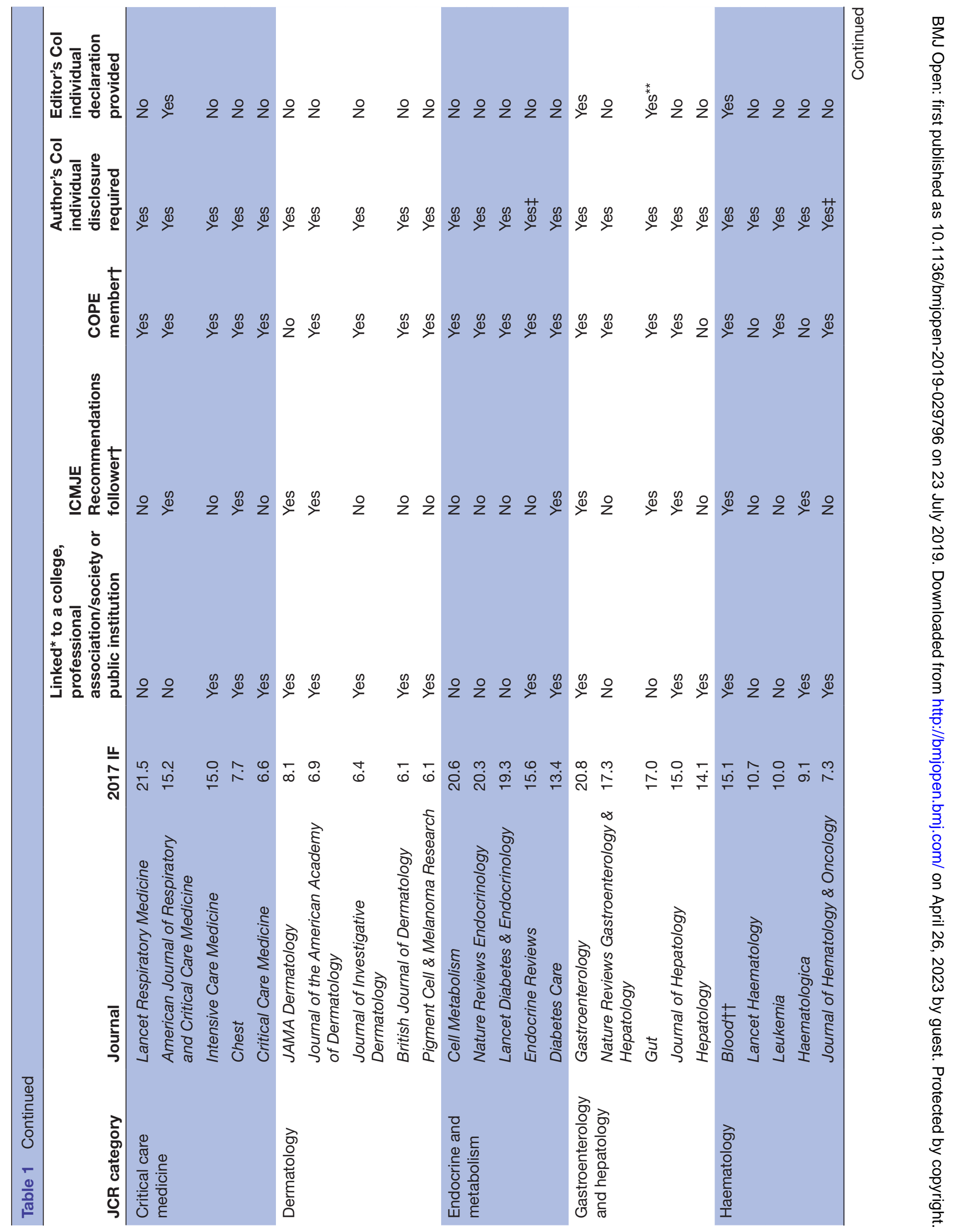




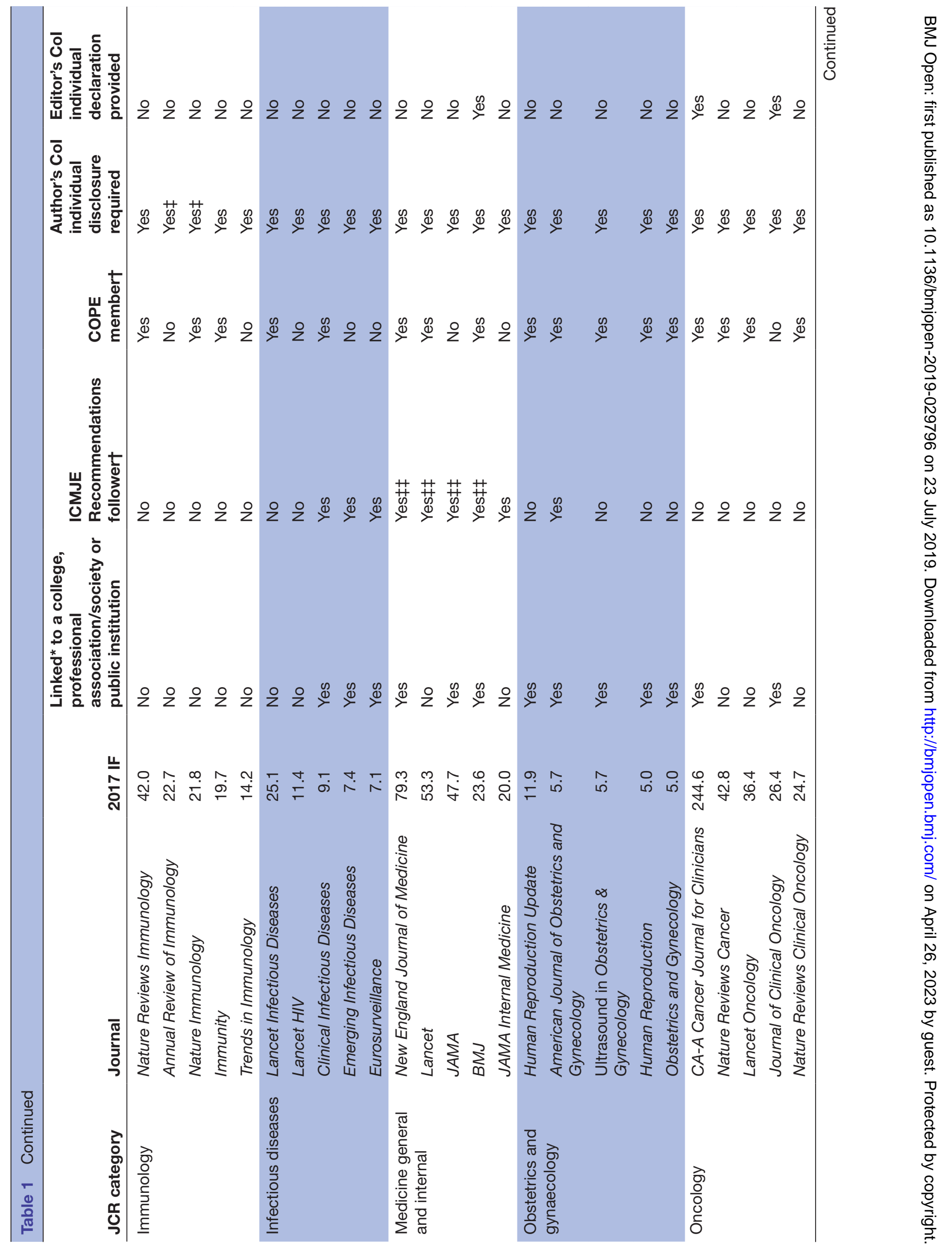




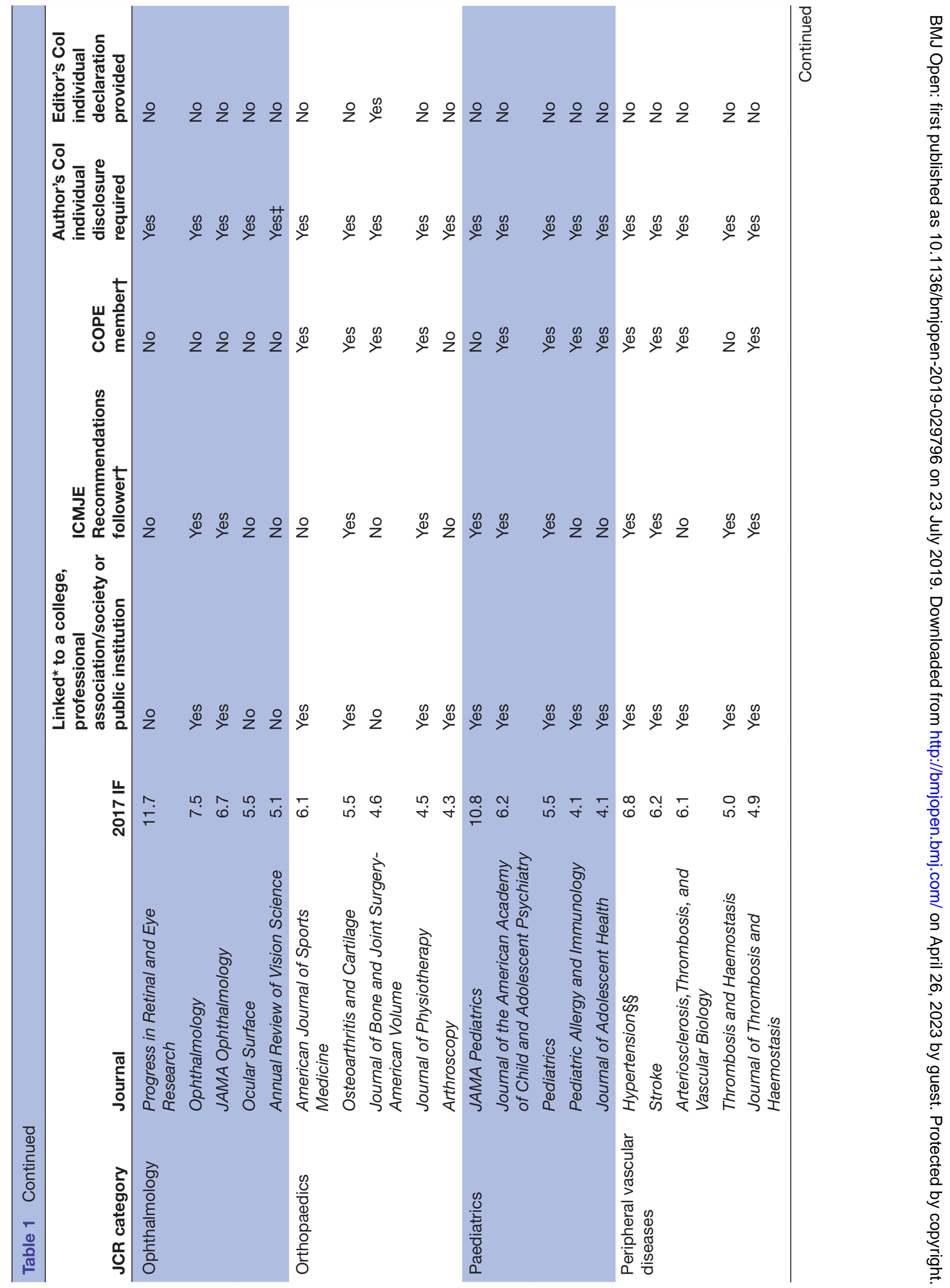




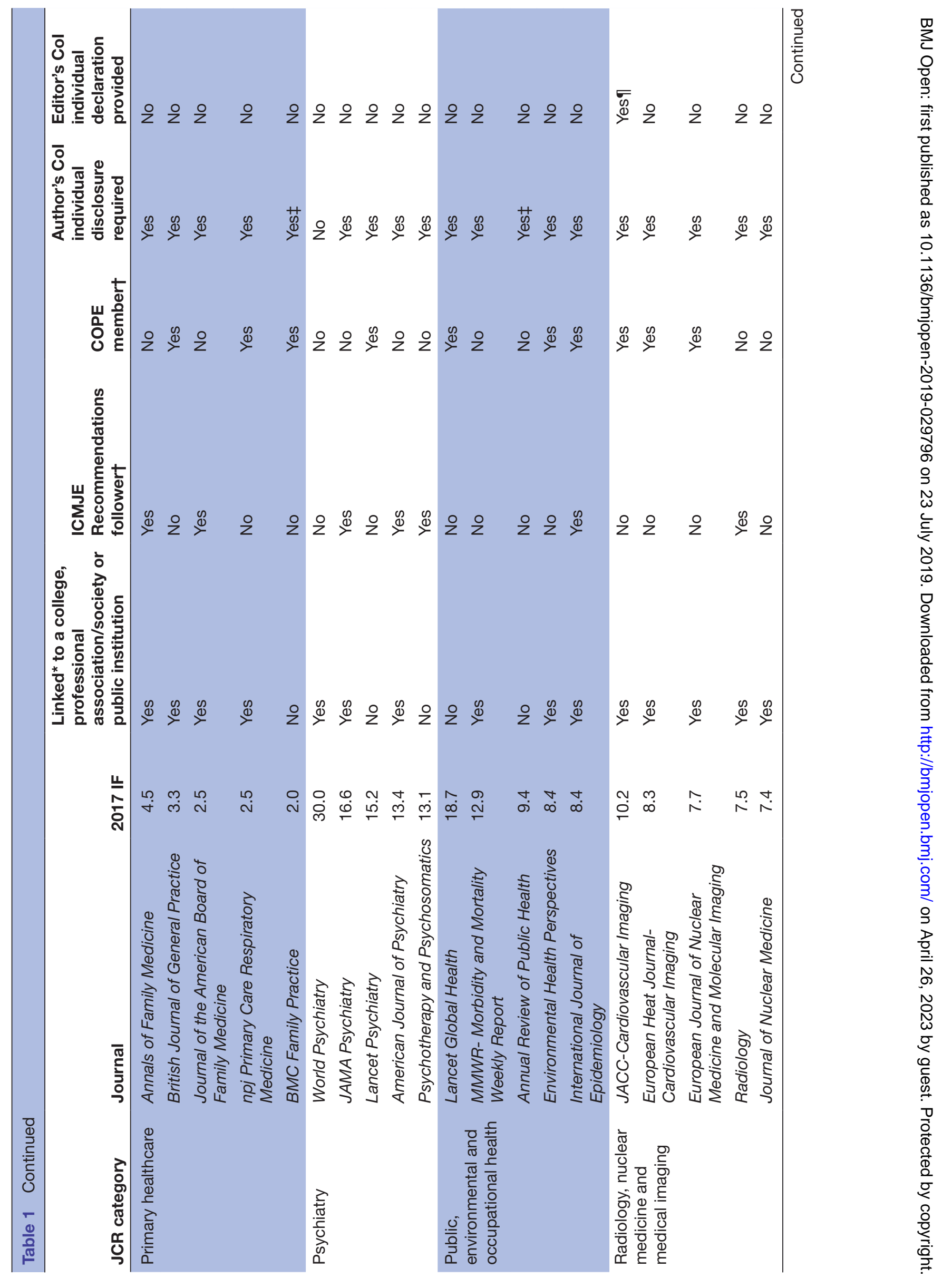




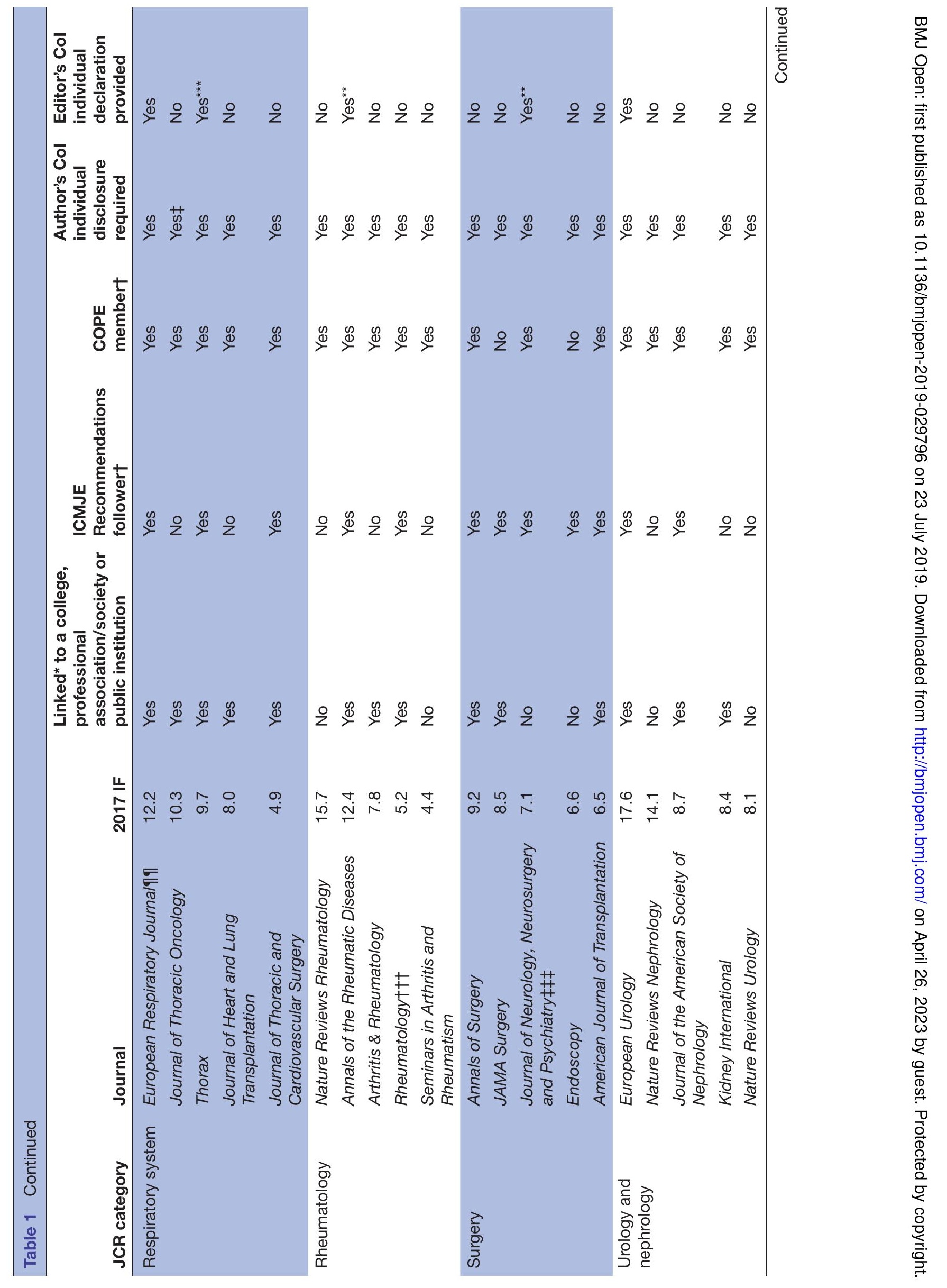


of Cardiology and JACC: Cardiovascular Imaging) were the only ones reporting the dollar amount received (modest or significant; threshold: $\$ 5000$ ) by each member of the editorial team. Finally, four journals belonging to the BMJ Group reported CoIs for one (Annals of the Rheumatic Diseases, Gut, and Journal of Neurology Neurosurgery) or three (Thorax) editors-but not all of them-whereas The BMJ reported individual potential CoIs for all members of its editorial team.

\section{DISCUSSION}

This study conducted on 130 high-impact medical journals from 26 medical JCR categories showed that although almost all (99\%) required authors to disclose potential CoIs at the time of manuscript submission, only $12 \%$ reported individual editors' potential CoIs. Editors' disclosure rarely happened among journals that, in $88.5 \%$ of cases, were followers of the ICMJE Recommendations and/or COPE members, which recommend regular disclosure of editorial CoI.

The situation in the rest of the thousands of journals that are included in the list of followers of the ICMJE Recommendations is even worse. We have shown previously that in a random sample of 350 journals only $1 \%$ $(2 / 350)$ of the journal websites had declarations on individual editors' potential CoIs, whereas 82\% (287/350) required disclosure of authors' CoIs. ${ }^{12}$

The USA OPD has shed light on editors' CoI by providing data on the payments by industry to journal editors also working as clinicians in the USA. In 2014, $51 \%$ and $20 \%$ of 713 of clinicians working as editors in 52 top medicine journals in 25 different specialties received general payments (eg, consultancy, honorariums, meals, travel) and research payments from industry, respectively. ${ }^{9}$ Although the monetary values varied substantially across specialties and journals, there were five editors that received general payments between US\$325000 and US\$11 million in 1 year. ${ }^{9}$ In $2015,46 \%$ (320/703) of editors from 60 influential USA journals in six medical specialties received general payments from industry, of whom $48 \%$ (152/320) received payments of more than US\$5000 - the threshold considered significant by the National Institutes of Health. ${ }^{10}$ In 2013-2016, 42\% $(141 / 333)$ of USA-based physician-editors working in 35 journals with the highest number of citations in 2015 in seven medical specialties received industry payments within any given year. ${ }^{11}$ Median general payments to editors were mostly higher compared with all physicians within the same specialty. ${ }^{11}$ Close to half of the editors of well-respected USA journals received industry payments, but very few disclosed them. However, the use of the USA OPD does not provide a complete picture since this database does not include payments to physician members of company corporate boards or payments from companies whose products have not been marketed. ${ }^{13}$

The situation in the European Union (EU) is unknown. France, Latvia and Portugal have regulations mandating 
the transparent reporting of payments by industry to healthcare professionals. ${ }^{14}$ In other EU countries, including Germany, Italy, Spain, Sweden, the Netherlands and the UK, industry self-regulations are in place. ${ }^{14}$

It has been observed that physicians accepting inexpensive meals from pharma companies prescribe more brand name medicines, ${ }^{15}$ and that greater payments were associated with greater proportion of branded prescriptions. ${ }^{16}$ What might be expected from editors who receive industry payments and could be involved in assessing manuscripts of industry-sponsored trials? The ICMJE Recommendations state that editors should recuse themselves from editorial decisions when they have potential CoIs. ${ }^{7}$ Thus, authors and readers have to presume that this happens if this is a journal's policy. Unfortunately, only $57 \%(34 / 60)$ of influential USA journals ${ }^{10}$ and $18 \%$ of journals listed as followers of the ICMJE Recommendations ${ }^{12}$ have a publicly available editor's CoI policy. So, in the best-case scenario, where all journals with editors' CoI policy have a recusal statement that is always followed, there is still a risk that editors of many journals with industry ties could engage in editorial decisions with manuscripts for which they have a conflict.

While many journals have addressed the disclosure of authors' potential CoI disclosure, few have had a similar approach to editors' CoIs. The decision taken by the editors of 18 orthopaedic journals to agree to use the ICMJE form for disclosing authors' CoIs from 2011 onwards is laudable, ${ }^{17}$ but as of January 2019 there has not been any such an agreement regarding editors' individual potential CoI disclosure. Similarly, Nature Research journals ${ }^{18}$ and JAMA Network journals ${ }^{19}$ have recently readdressed their authors' potential CoI disclosure requirements but have not done the same regarding editors' individual disclosures.

The limitations of this study are that all information was retrieved from journals that lead their respective medical specialties and logically the number was relatively small. However, and as mentioned above with respect to the percentage of ICMJE Recommendations followers that declared the individual authors' and editors' CoI, we should foresee that among all medical journals the percentage that requires disclosure of these CoIs will be much smaller.

It is paradoxical that many journals ask for full authors' CoI disclosure, whereas almost all of them provide no publicly available information on their editors' potential CoIs. The 14 ICMJE member journals should lead the way in adhering to their own policies. Journals that belong to professional societies/associations should also disclose their editorial teams' individual potential CoI. Finally, all journals that are listed as followers of the ICMJE Recommendations should behave accordingly and report their editors' individual potential CoI.

The publication process-as a critical part of the scientific enterprise-should be based on the transparent behaviour of all agents involved. Journal editorial teams are a key player that should apply to themselves the transparency they demand from their authors, by at least regularly updating their individual CoI declarations in an easily accessible place at the journal's website.

Contributors RD-R conceived the idea and wrote the first draft of the manuscript. $\mathrm{RD}-\mathrm{R}$ retrieved all the data. AM checked the consistency of all the information from a random sample of $25 \%$ of the 130 journals. ALC and AM provided comments and edits throughout the drafting process for important intellectual content. RD-R, ALC and AM approved the final version of the manuscript and are accountable for all aspects included in it. The authors assume full responsibility for the accuracy and completeness of the data and ideas presented.

Funding The authors have not declared a specific grant for this research from any funding agency in the public, commercial or not-for-profit sectors.

Competing interests All authors declare neither financial nor non-financial interests that may be relevant to the submitted work. AM declares that she participated in the creation of the ICMJE Form for Disclosure of Potential Conflicts of Interest.

Patient consent for publication Not required.

Ethics approval Not required

Provenance and peer review Not commissioned; externally peer reviewed.

Data availability statement All data relevant to this study are inlcuded in the article.

Open access This is an open access article distributed in accordance with the Creative Commons Attribution Non Commercial (CC BY-NC 4.0) license, which permits others to distribute, remix, adapt, build upon this work non-commercially, and license their derivative works on different terms, provided the original work is properly cited, appropriate credit is given, any changes made indicated, and the use is non-commercial. See: http://creativecommons.org/licenses/by-nc/4.0/.

\section{REFERENCES}

1. Ornstein C, Thomas K. Top cancer researcher fails to disclose corporate financial ties in major research journals. New York times, September 8, 2018. Available: https://www.nytimes.com/2018/09/08/ health/jose-baselga-cancer-memorial-sloan-kettering.html?module= inline

2. Ornstein C, Thomas K. Sloan Kettering researchers correct the record by revealing company ties. New York times, October 12 2018. Available: https://www.nytimes.com/2018/10/12/health/ memorial-sloan-kettering-cancer-disclosure.html

3. Wiersma M, Kerridge I, Lipworth W, et al. Should we try to manage non-financial interests? BMJ 2018;361:k1240.

4. Shawwa K, Kallas R, Koujanian S, et al. Requirements of clinical journals for authors' disclosure of financial and non-financial conflicts of interest: a cross sectional study. PLoS One 2016;11:e0152301.

5. Wayant C, Turner E, Meyer C, et al. Financial conflicts of interest among oncologist authors of reports of clinical drug trials. JAMA Oncol 2018;4:1426-8.

6. Kleinert S, Wager E, COPE. Responsible research publications: international standards for editors. A position statement developed at the 2nd world conference on research integrity, Singapore, July 22 24, 2010. Available: https://publicationethics.org/files/International\% 20standard_editors_for\%20website_11_Nov_2011.pdf

7. ICMJE. International Committee on medicine journals editors. Recommendations for the conduct, reporting, editing, and publication of scholarly work in medical journals, December 2018. Available: http://www.icmje.org/icmje-recommendations.pdf

8. Marušić A, Dal-Ré R. Getting more light into the dark room of editorial conflicts of interest. J Glob Health 2018;8:010101.

9. Liu JJ, Bell CM, Matelski JJ, et al. Payments by US pharmaceutical and medical device manufacturers to US medical journal editors: retrospective observational study. BMJ 2017;359:j4619.

10. Haque W, Minhajuddin A, Gupta A, et al. Conflicts of interest of editors of medical journals. PLoS One 2018;13:e0197141.

11. Wong VSS, Avalos LN, Callaham ML. Industry payments to physician Journal editors. PLoS One 2019;14:e0211495.

12. Dal-Ré R, Marušić A. Are journals following the ICMJE recommendations complying with conflicts of interest disclosure policies. Eur J Intern Med 2018;57:e17-9.

13. Agrawal S, Brennan N, Budetti P. The Sunshine Act--effects on physicians. N Engl J Med 2013;368:2054-7. 
14. Fabbri A, Santos Ala, Mezinska S, et al. Sunshine policies and murky shadows in Europe: disclosure of pharmaceutical industry payments to health professionals in nine European countries. Int $J$ Health Policy Manag 2018;7:504-9.

15. DeJong C, Aguilar T, Tseng C-W, et al. Pharmaceutical industrysponsored meals and physician prescribing patterns for Medicare beneficiaries. JAMA Intern Med 2016;176:1114-22.
16. Perlis $\mathrm{RH}$, Perlis CS. Physician payments from industry are associated with greater Medicare Part D prescribing costs. PLOS One 2016;11:e0155474.

17. Disclosure of conflict of interest (edit). J Surg Orthop Adv 2011;20:151.

18. Outside interests (edit). Nature 2018;554:6.

19. Bauchner H, Fontanarosa PB, Flanagin A. Conflicts of interests, authors, and journals. JAMA 2018;320:2315-8. 